\title{
Runoff sampler for small agricultural watersheds ${ }^{\alpha}$
}

\author{
P. Pathak \\ Resource Management Program; International Crops Research Institute for the Semi-Arid Tropics \\ (ICRISAT), Patancheru P.O., Andhra Pradesh 502 324, India
}

(Accepted 11 September 1990)

\begin{abstract}
Pathak, P., 1991. Runoff sampler for small agricultural watersheds. Agric. Water Manage., 19: 105115.

Development and testing of a simple runoff sampler which can be used to monitor the quantity of sediment carried by runoff from small agricultural watersheds is presented. The sampler uses the rapidly fluctuating flow nature to account for the temporal variation in sediment concentration. Intensive laboratory testing was carried out for sampler efficiencies at various flow and sediment conditions. Overall efficiency obtained was in the range of 87 to $98 \%$. The sediment catching efficiencies for clay, silt, fine sand and coarse sand particles were $96 \%, 87 \%, 75 \%$ and $60 \%$, respectively. The sampler has been in use for the last 4 years in the field and its general performance has been satisfactory.
\end{abstract}

\section{INTRODUCTION}

Soil erosion on cultivated land is the cause of many processes, whose mechanics and control are not well understood. This recognition has led to intensive research aimed at understanding these processes and the development of management measures to control erosion and correct problems created by past practices. At the International Crops Research Institute for the SemiArid Tropics (ICRISAT) and other places, small agricultural watersheds ( 1 to $100 \mathrm{ha}$ ) have been the focus for such studies. One of the important aspects in carrying out such studies is the precise measurement of soil erosion.

Runoff samplers have been extensively used for monitoring the sediments from experimental areas. Among the best known and most widely used are the Coshocton wheel runoff sampler and the multislot devisor; both have been reported to perform satisfactorily in the field when properly installed and maintained (Carter and Parsons, 1967; Wang et al., 1971; Parsons, 1954). However, the use of these samplers has usually been restricted to watersheds of less than 1 ha primarily because of their limited capacity. A traversing slot

\footnotetext{
${ }^{\alpha}$ Journal Article No. 213, International Crops Research Institute for the Semi-Arid Tropics (ICRISAT), Patancheru P.O., Andhra Pradesh 502 324, India.
} 
runoff sampler has been developed for small watersheds (Dendy, 1975), but the complications associated with the mechanical and electrical components viz. motor, battery, etc. in this sampler may inhibit its general field use.

The USDH-48 (depth integrating), USP-61 (point integrating), Neyrpic sediment sampler and many others (Vanoni, 1975; Murthy, 1971) have been developed for sampling runoff from large watersheds.

The use of currently available runoff samplers for monitoring the sediments from small agricultural watersheds is limited. The typical sediment concentration variation during runoff from these watersheds needs special consideration in designing the runoff sampler. This paper describes a simple runoff sampler developed to meet the requirements of sediment monitoring from such small watersheds. The sampler was tested in a hydraulic laboratory and at an operational research watershed; the test results obtained are reported.

\section{SEDIMENT VARIATION DURING THE FLOW}

Extreme variation in sediment concentration has been reported during the runoff from small agricultural watersheds (ICRISAT, 1976-77). Figure 1 shows the variation in time of sediment concentration during two runoff events, measured at the same watershed. In the first runoff event, the hydrograph segment $a b c d$, which accounts for only $15 \%$ of the total runoff duration and $41 \%$ of the total runoff volume, produced nearly $80 \%$ of the storm soil loss. Similarly during_the_second event, the hydrograph segment mnop accounts for $75 \%$ of total soil loss.

Similar trends in the distribution of soil loss were observed from most of the runoff events which were recorded from research watersheds over a period of 5 years. The relative distribution and occurrence of the major portion

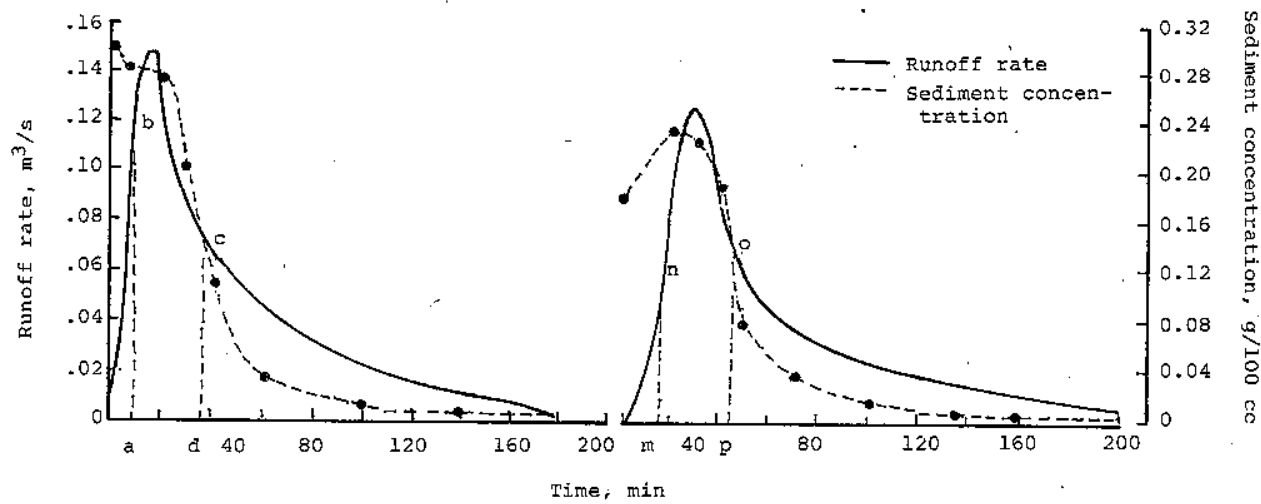

Fig. 1. Variation in time of sediment concentration during two runoff events, measured at the same watershed. 
of soil loss during a segment of the runoff hydrograph provide two important design criteria for runoff samplers.

(1) The time variation in sediment load is relatively more important than the horizontal and vertical variation, and should be taken as the first factor in designing the runoff sampler for small agricultural watersheds.

(2) The runoff sampler should be designed to monitor efficiently the sediment quantity particularly for the hydrograph segment at or near the peak rate since this segment accounts for the major portion of storm soil loss.

\section{WORKING PRINCIPLE AND OPERATION OF THE RUNOFF SAMPLER}

To simplify the design of the runoff sampler, the momentary or instantaneous fluctuations in sediment concentration across a flow section are avoided, mainly by selecting the sampling site to be downstream of a high turbulence point where the sediment variation across the flow section is minimized. The point with substantial turbulence could easily be located on the downstream portion of the runoff measuring devices commonly used on small watersheds.

The rapidly fluctuating nature of runoff flow from small watersheds and its relationship with time is used in the sampler to account for the time variation in sediment loads. This is achieved by taking representative samples for different hydrograph segments by collecting the samples at different flow depths. The samples are taken through small diameter pipes which are kept at specified heights from the bed of the channel (Fig. 2). These pipes are connected to separate containers by plasstic pipes. The working principle of the sampler

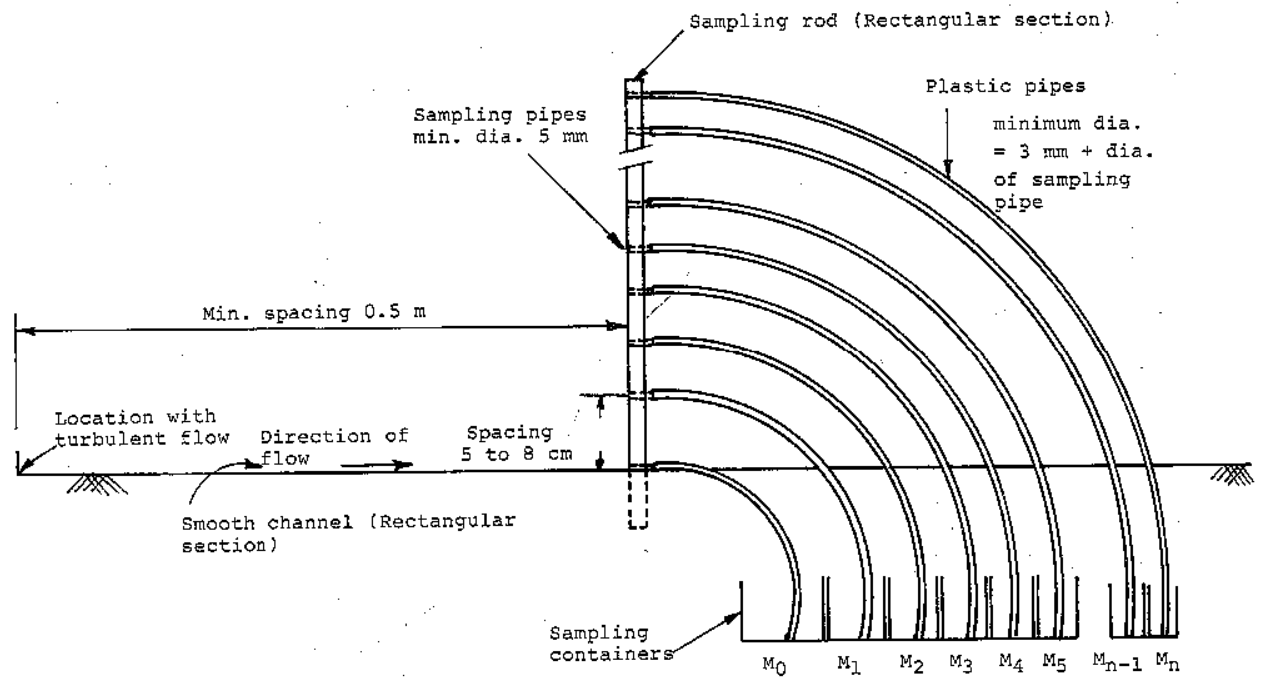

Fig. 2. Schematic of the sampler. 


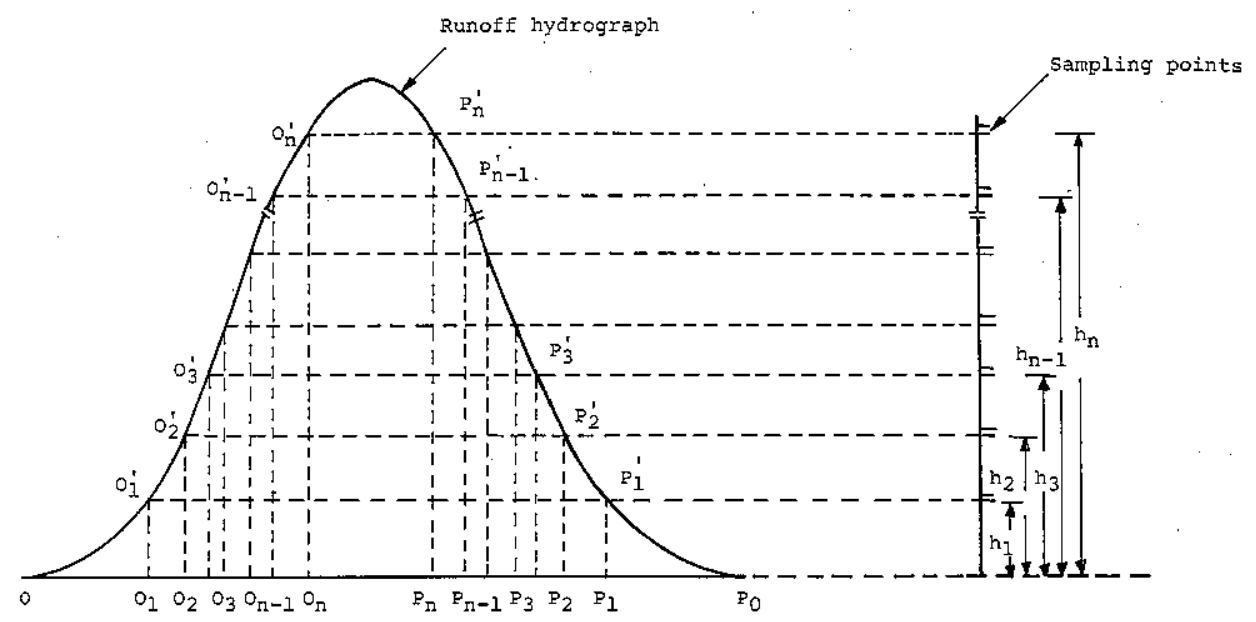

Fig. 3. Working principle of the sampler.

is explained in Fig. 3. A single peak runoff hydrograph is taken as an example to explain the operation of the sampler. The lowest sampling pipe takes the sample throughout the total runoff period while the upper sampling pipes, depending upon their relative positions, take samples for shorter periods. The sample volume and sediment concentration for each container are determined individually. The sediment concentration of the runoff samples is determined using the pipet method (Vanoni, 1975). Recorded hydrographs at the runoff measuring strüctüre are used to determine the runoff hydrographs at the sampling location. The actual sediment concentrations for the different hydrograph segments and total soil loss are calculated in the following manner.

Assume $V s_{0}, V s_{1}, V s_{2}, \ldots, V s_{n}$ and $C s_{0}, C s_{1}, C s_{2}, \ldots, C s_{n}$ are the volumes and sediment concentrations of the runoff samples collected in the containers $M_{0}$, $M_{1}, M_{2}, \ldots, M_{n}$, respectively.

$V_{0}, V_{1}, V_{2}, \ldots, V_{n-1}, V_{n}$ and $C_{0}, C_{1}, C_{2}, \ldots, C_{n-1}, C_{n}$ are the runoff flow volumes and average sediment concentrations for the hydrograph segments, $O O_{1}^{\prime} O_{1}+P_{1} P_{1}^{\prime} P_{0}, \quad O_{1} O_{1}^{\prime} O_{2}^{\prime} O_{2}+P_{2} P_{2}^{\prime} P_{1}^{\prime} P_{1}, \quad O_{2} O_{2}^{\prime} O_{3}^{\prime} O_{3}+P_{3} P_{3}^{\prime} P_{2}^{\prime} P_{2}, \quad \ldots$, $O_{n-1} O_{n-1}^{\prime} O_{n}^{\prime} O_{n}+P_{n} P_{n}^{\prime} P_{n-1}^{\prime} P_{n-1}, O_{n} O_{n}^{\prime} P_{n}^{\prime} P_{n}$.

The containers $M_{0}, M_{1}, M_{2}, \ldots, M_{n-1}, M_{n}$ will collect the runoff samples only when the depth of flow will be equal or greater than $h_{0}, h_{1}, h_{2}, \ldots, h_{n-1}$, $h_{n}$.

The container $M_{n}$ collects the sample only during the hydrograph segment $O_{n} O_{n}^{\prime} P_{n}^{\prime} P_{n}$. Therefore its sediment concentration will also represent the average sediment concentration for the segment, which means $C s_{n}$ equal to $C_{n}$. The soil loss during the hydrograph segment $O_{n} O_{n}^{\prime} P_{n}^{\prime} P_{n}$ will be

$V_{n} C_{n}=V_{n} C s_{n}$. 
The container $M_{n-1}$ collects the sample during the hydrograph segments $O_{n-1} O_{n-1}^{\prime} O_{n}^{\prime} O_{n}+P_{n} P_{n}^{\prime} P_{n-1}^{\prime}$ and $O_{n} O_{n}^{\prime} P_{n}^{\prime} P_{n}$. Therefore its concentration does not represent just one particular hydrograph segment. During the hydrograph segment $O_{n} O_{n}^{\prime} P_{n}^{\prime} P_{n}$, the container $M_{n-1}$ collects the sample of volume $V s_{n}$ with concentration $C s_{n}$. The volume of the sample collected in container $M_{n-1}$ during the hydrograph segment $O_{n-1} O_{n-1}^{\prime} O_{n}^{\prime} O_{n}+P_{n} P_{n}^{\prime} P_{n-1}^{\prime} P_{n-1}$ will be $V s_{n-1}-V s_{n}$.

Similarly the total amount of sediment collected in container $M_{n-1}$ could be divided into two parts, one the amount collected during the hydrograph segment $O_{n} O_{n}^{\prime} P_{n}^{\prime} P_{n}$ and the second during the hydrograph segment $O_{n-1} O_{n-1}^{\prime} O_{n}^{\prime} O_{n}+P_{n} P_{n}^{\prime} P_{n-1}^{\prime} P_{n-1}$. The total sediment in container $M_{n-1}$ would be written as

$$
V s_{n-1} C s_{n-1}=V s_{n} C s_{n}+\left(V s_{n-1}-V s_{n}\right) C_{n-1}
$$

or

$C_{n-1}=\frac{V s_{n-1} C s_{n-1}-V s_{n} C s_{n}}{V s_{n-1}-V s_{n}}$.

Therefore the soil loss during the segments $O_{n-1} O_{n-1}^{\prime} O_{n}^{\prime} O_{n}+$ $P_{n} P_{n}^{\prime} P_{n-1}^{\prime} P_{n-1}$ will be

$V_{n-1} C_{n-1}=V_{n-1}\left(\frac{V s_{n-1} C s_{n-1}-V s_{n} C s_{n}}{V s_{n-1}-V s_{n}}\right)$

Similar equations for the soil loss during the other hydrograph segment can be derived. The soil loss during the last hydrograph segment $O O_{1} O_{0}^{\prime}+P_{1} P_{1}^{\prime} P_{0}$ will be

$C_{0} V_{0}=V_{0}\left(\frac{V s_{0} C s_{0}-V s_{1} C s_{1}}{V s_{0}-V s_{1}}\right)$

Therefore the total soil loss $S_{\mathrm{t}}$, for the storm will be

$$
\begin{aligned}
S_{\mathrm{t}}= & V_{0}\left(\frac{V s_{0} C s_{0}-V s_{1} C s_{1}}{V s_{0}-V s_{1}}\right)+V_{1}\left(\frac{V s_{1} C s_{1}-V s_{2} C s_{2}}{V s_{1}-V s_{2}}\right)+\ldots \\
& +V_{n-1}\left(\frac{V s_{n-1} C s_{n-1}-V s_{n} C s_{n}}{V s_{n-1}-V s_{n}}\right)+V_{n} C s_{n}
\end{aligned}
$$

The values of $V_{0}, V_{1}, V_{2}, \ldots, V_{n}$ can be calculated from the runoff hydrograph, while the values of $V s_{0}, V s_{1}, \ldots, V s_{n}$ and $C s_{0}, C s_{1}, \ldots, C s_{n}$ can be determined from the samples collected in containers $M_{0}, M_{1}, \ldots, M_{n}$.

Although for estimating the total storm soil loss, this developed sampler uses the concept of dividing the entire runoff hydrograph into several small segments. But it does not provide the sediment concentration versus time 
relationship. It provides only the average sediment concentrations of the pair hydrograph segments (one on the rising side and another on recession side of the hydrograph).

\section{CONSTRUCTION AND INSTALLATION}

The fabrication of the sampler is quite simple and can be done with readily available materials. The dimensions of the sampler are shown in Fig. 2 . The critical components are the sampling pipes which are welded on a rectangular metal rod. The materials and cross section of the rod are chosen to meet the requirement of low vibration in the rod during the flow. Low vibration is important for accurate sampling. The intake approach conditions for all the sampling pipes are kept similar, a minor difference may result in considerable change in sampling rates. Plastic pipes of slightly larger diameter than the sampling pipes are used to avoid additional resistance to the sampled flow. The number of sampling pipes and their spacing are determined on the basis of desired accuracy and sediment flow condition. A wider spacing between the sampling pipes on the lower portion and relatively closer spacing, on the upper part of the sampling rod may be used. Containers of different sizes are used, as the sample volumes to be collected vary in each container. The metallic rod holding the sampling pipes is firmly fixed in the concrete channel bed. The distance between the sampling point and turbulence location is very critical and the selection should be made on the basis of the expected degree of turbulence (Fig. 2).

\section{SAMPLER TESTING IN THE LABORATORY}

Intensive laboratory testing of the sampler was carried out to determine the sampler efficiencies at various flow conditions. Sampling pipes of $5 \mathrm{~mm}$ diameter were used during the tests. The sampler, a one foot Parshall flume,

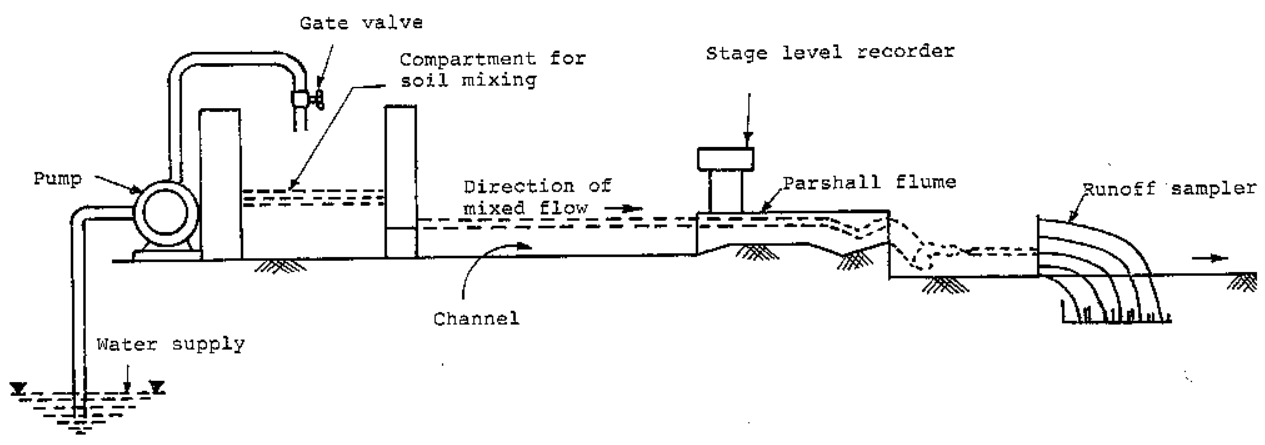

Fig. 4. Installation scheme of the sampler. 
and a stage level recorder for measuring the flow volume and rate were installed on a smooth cemented channel (Fig. 4). Two high discharge pumps with valves for controlling the rates of flow were used to deliver water to the channel. Two soils of different textures (Table 1 ) were used in the tests. During each run of 12 minutes, a known soil amount was mixed with the water which passes through the flume and the sampler. The flow rate was varied by controlling the gate valve while the soil mixing rate was varied manually. This was done to simulate flows similar to those which occur in the field. The samples collected from each container were analyzed. A textural analysis of the sample soil was carried out after each run. The mass of dry soil delivered to the sampler was calculated as the mass of soil introduced into the mixing compartment, corrected for moisture content, minus the measured amount deposited in the approach channel.

The sampler efficiencies for two soils, as affected by the depth of the flow, are shown in Fig. 5. A general decrease in sampler efficiency was observed

\section{TABLE 1}

Soil texture used in testing (USDA System).

\begin{tabular}{lll}
\hline Texture & $\begin{array}{l}\text { Soil A } \\
(\%)\end{array}$ & $\begin{array}{l}\text { Soil B } \\
(\%)\end{array}$ \\
\hline Clay & 55 & 40 \\
Silt & 26 & 30 \\
Fine sand & 9 & 17 \\
Medium sand & 5 & 6
\end{tabular}

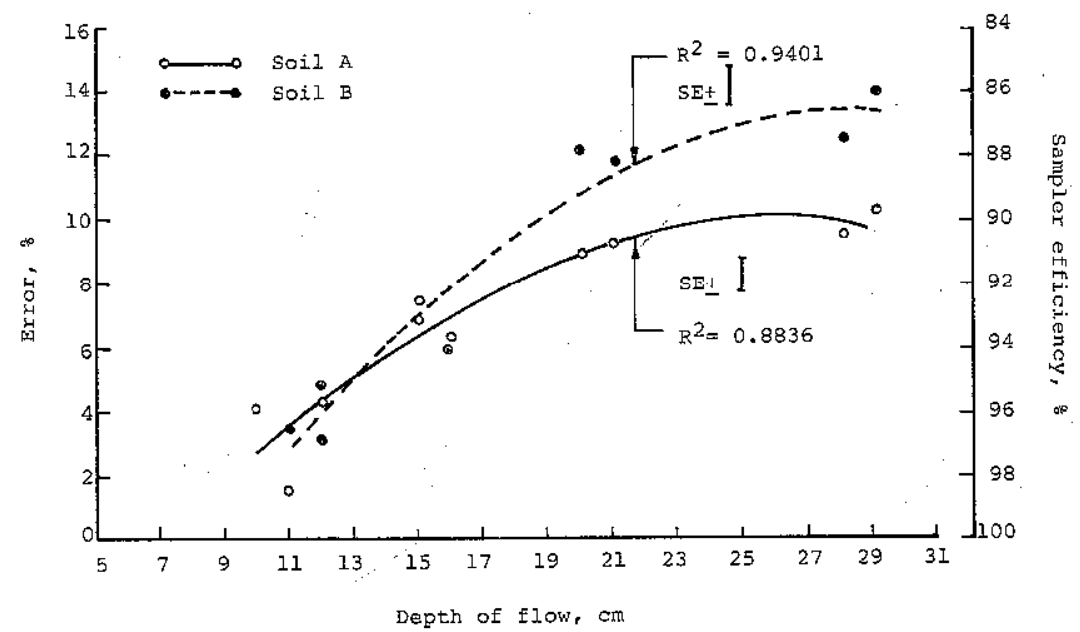

Fig. 5. Sampler efficiencies for two soils, as affected by the depth of the flow. 
with increase in the flow depth, the efficiency for the coarse textured soil B being influenced more than that for the fine textured soil $\mathrm{A}$. The reason seems to be that, even after the turbulence, the coarse soil particles may not have been uniformly distributed at the sampling flow section. Reasonably good

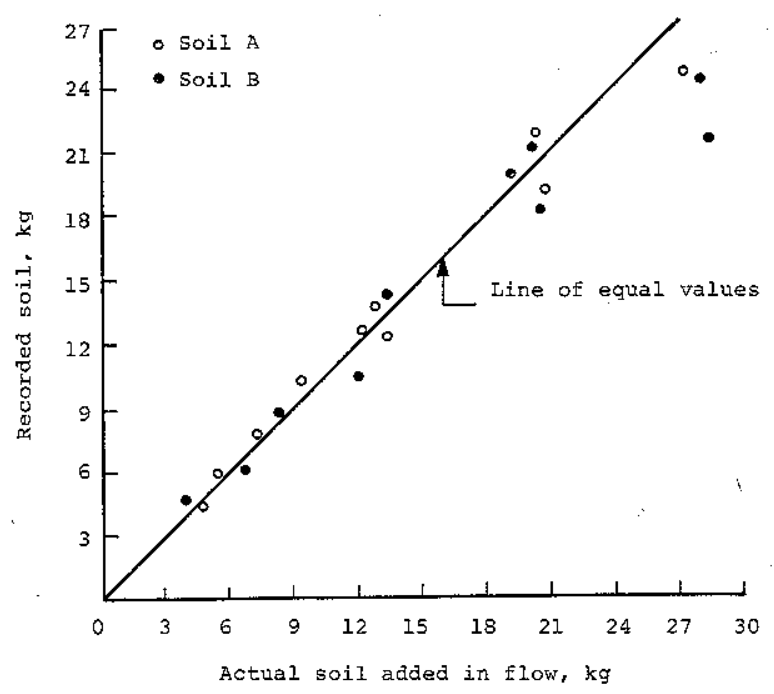

Fig. 6. Relationship between actual amount of soil added and the amount measured by the sampler.

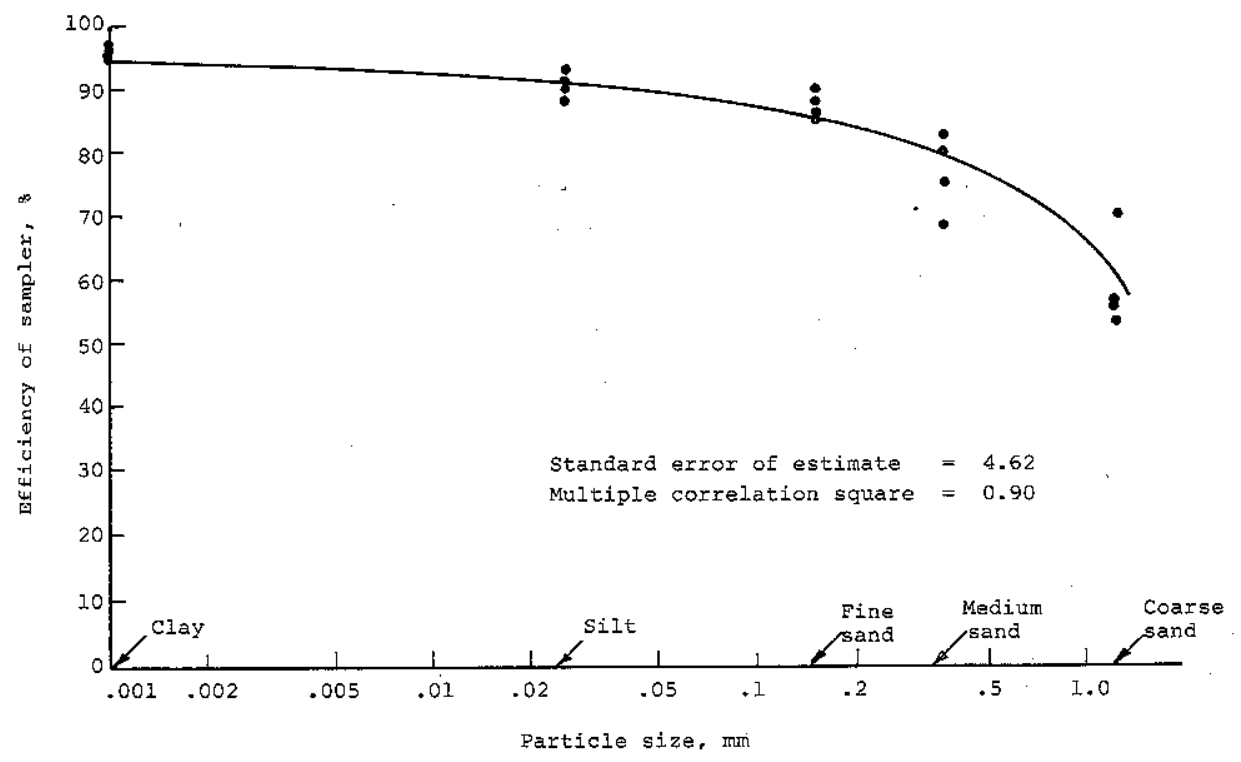

Fig. 7. Catching efficiency of the sampler for different particle sizes. 
agreement was obtained (Fig. 6) between the actual amount of soil added to the flow and the amount measured by the sampler for both soils. However, better agreement was observed with the finer soil A.

Figure 7 shows the catching efficiency of the sampler for the different particle sizes of sediments. The average catching efficiency was as high as $96 \%$ for clay particles while for coarse sand it is as low as $60 \%$; however, the low efficiency for coarse sand may not effect the overall sampler efficiency because in the eroded soil, the percentage of such materials are usually in the range of 1 to $6 \%$.

\section{FIELD PERFORMANCE}

For field tests the sampler was installed below a 2 foot Parshall flume on a Vertisol watershed. The details of the watershed, soil, surface cover and run-

\section{TABLE 2}

Watershed, crops and runoff events details related to field testing of sediment sampler.

Watershed details: area $=3.5$ ha; average slope $=1.5 \%$; soil type: Vertisol (Typic Pellustert).

Soil texture:

Depth

(cm)

$0-15$

$15-30$

$30-60$

$60-90$

Distribution (\%)

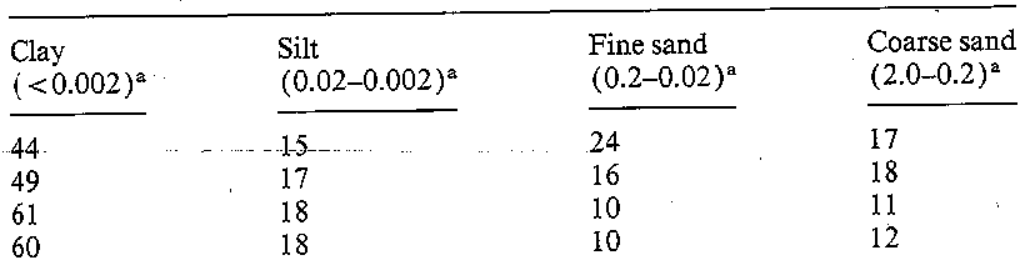

Crops and cropping system:

The following crops in rotation were taken:

$-50 \%$ of the watershed area under maize/chickpea sequential cropping;

- the remaining $50 \%$ area under sorghum + pigeonpea intercrop.

Surface cover: Stubbles small quantity (about $1 \mathrm{t} / \mathrm{ha}$ ).

Runoff events details: Major runoff events during testing period of 3 years

\begin{tabular}{rll}
$\begin{array}{c}\text { Amount } \\
(\mathrm{mm})\end{array}$ & & $\begin{array}{l}\text { Peak runoff rate } \\
\left(\mathrm{m}^{3} / \mathrm{s}\right)\end{array}$ \\
\cline { 1 - 1 } 27 & & 0.465 \\
20 & & 0.115 \\
11 & & 0.020 \\
170 & & 0.830 \\
50 & & 0.175 \\
9 & & 0.215 \\
8 & & 0.155 \\
42 & & 0.415 \\
24 & & 0.160
\end{tabular}

${ }^{2}$ Values in parentheses are particle diameters $(\mathrm{mm})$. 


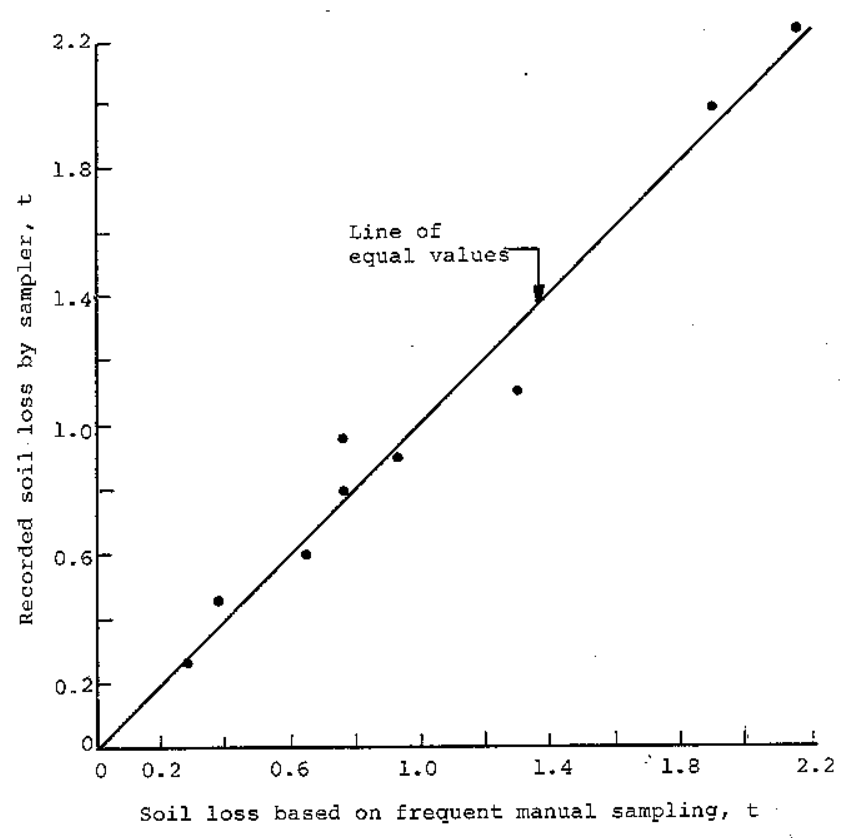

Fig. 8. Relationship between the soil loss calculated and that recorded by the sampler.

off events, related to field testing of sampler are given in Table 2 . The sampler has been used for the last four years. The overall performance has been satisfactory. As the sampler-does not have any moving component, maintenance requirements have been minimal. For evaluating the sampler accuracy in the field, the actual soil loss for all the major storms was determined by taking the frequent samples during the different parts of the runoff hydrograph. The sediment concentration obtained from such samples was superimposed on the runoff hydrograph which was obtained from the stage level recorder. For each individual hydrograph segment the soil loss was calculated. The storm soil loss was estimated by adding the soil loss of different hydrograph segments. Good agreement was observed between the soil loss calculated on this basis and that recorded by the sampler (Fig. 8 ).

\section{LIMITATIONS}

The developed sampler has the following limitations:

(1) This sampler is not efficient where the eroded sediments contains a very high percentages of medium and coarse sands.

(2) For storms having multiple peaks (more than two) its accuracy to estimate soil loss is low.

(3) This sampler is useful only for small watersheds (probably less than 400 
ha). The main point is that there should be strong fluctuations in flow depths with time.

\section{CONCLUSION}

The simple runoff sampler developed can be used for estimating the soil loss from small agricultural watersheds. The expected overall sampler efficiency for clay and clay loam soils is in the range of 87 to $98 \%$. As the developed sampler does not have any moving component, its maintenance requirements is minimal.

\section{ACKNOWLEDGEMENT}

The author is highly thankful to Dr. J. Kampen and Dr. S.M. Miranda for the encouragement, suggestions and keen interest in this work.

\section{REFERENCES}

Carter, C.E. and Parsons, D.A., 1967. Field test on the Coshocton type wheel runoff sampler. Trans. ASAE, 10(1): 133-135.

Dendy, F.E., 1975. Traversing slot runoff sampler for small watersheds. ARS-S-15, USDA Sedimentation Laboratory, Alabama, North Mississippi Area, Southern Region, USDA, Oxford.

ICRISAT (International Crops Research Institute for the Semi-Arid Tropics), 1976-77. Annual Report, ICRISAT, Patancheru P.O., Andhra Pradesh, 502 324, India.

Murthy, B.N., 1971. Discussion of sediment measurement techniques. B. Reservoir deposits by the Task Committee on Preparation of Sedimentation Manual, Committee on Sedimentation of the Hydraulics Division, Vito A. Vanoni (Editor), Chmn Journal of the Hydraulics Division, ASCE, Vol. 97, No. HY6. Proc. Paper 8155.

Parsons, D.A., 1954. Coshocton type wheel runoff samplers laboratory investigations. US Dept. Agric. Soil Conserv. Ser. TP-124.

Vanoni, V.A. (Editor), 1975. Sedimentation Engineering. Manuals and Reports on Engineering Practice, No. 54. ASCE, New York, 745 pp.

Wang, J.Y., Hermanson, R.E. and Hendrick, J.G., 1971. Modification of H flume and Coshocton wheel system. Trans. ASAE, 14(6): 1015-1017. 